\title{
Engaging head and heart in disciplinary learning: Insights from a threshold concepts-infused university programme
}

\author{
Jessica Goebel $^{1}$ and Suriamurthee Maistry ${ }^{2}$ \\ ${ }^{1}$ School of Accounting, Economics and Finance, University of KwaZulu-Natal \\ ${ }^{2}$ School of Education, University of KwaZulu-Natal \\ Corresponding Author: schroenn@ukzn.ac.za
}

(Submitted: 24 October 2019; Accepted: 14 February 2020)

\begin{abstract}
Deeper understanding of the factors that influence the course of disciplinary learning could help educators to facilitate the process more effectively. The Threshold Concepts Framework (TCF) encompasses cognitive, affective, and contextual aspects of learning, but has not fully examined the dynamics of the process. We explored students' experiences in a TCF-aligned, cooperative learning programme in economics at a South African university. Through Interactive Qualitative Analysis, data was generated through focus groups, interviews, and written reflections. From the detailed descriptions of their learning, rendered in students' voices, we abstract a representation of disciplinary learning as a challenging and transformative process, requiring that students engage with both head (cognition and metacognition) and heart (conation, affect, and identity). If the discipline as experienced aligns with students' sense of self, learning is more likely to be meaningful, facilitating the engagement of their inner resources to sustain academic commitment and enhance cognitive and metacognitive development.
\end{abstract}

Keywords: cooperative learning, disciplinary learning, identity, Interactive Qualitative Analysis, Threshold Concepts Framework

\section{Introduction}

Disciplinary learning in higher education can make steep demands of students, as they strive to master new ways of knowing and come to terms with shifting views on the world. The body of scholarship that has become known as the Threshold Concepts Framework (TCF) (Land, 2016; Meyer and Land, 2006a) offers a wide perspective on disciplinary learning that encompasses cognitive and affective aspects and accommodates contextual considerations. The TCF has generated reflection, discussion, and new ways of thinking about teaching and learning in higher education. However, work within the framework has not yet fully explored the dynamics of disciplinary learning, or the factors that may drive, enable or obstruct learning. Deeper understanding of the experiences and processes that disciplinary learning entails for students could help teachers in higher education to support and facilitate learning, particularly for students 
who struggle with the transition to university study and the challenges of disciplinary mastery (Cross and Carpentier, 2009).

We set out to deepen understanding of disciplinary learning, in a case study centred on a learning programme in economics at a South African university. The TCF framed our study and informed the content and task design of the programme. In this paper, we draw on students'accounts of their learning on the programme to work towards a model that represents and explains some of the inner mechanisms of disciplinary learning. We argue that the model adds to the understanding of learning inherent in the TCF and may have resonance beyond the immediate context.

The TCF is premised on the idea that in probably all disciplines, particular concepts serve as gateways to disciplinary thinking. Reaching understanding of such a 'threshold concept' ${ }^{1}$ in any field is likely to be experienced as transformative, precipitating conceptual and ontological shifts; probably irreversible; integrative (revealing interconnections among concepts); possibly bounded (serving to demarcate the discipline); and potentially (possibly inherently) troublesome, because of particular features of the knowledge to be gained (Meyer and Land, 2006a; Perkins, 2006). Although threshold concepts themselves are inherently disciplinary, the approach transcends disciplinary boundaries as it 'derives from the universality of student experiences of difficulty in encounters with [deeply challenging] content in any — and all — of their respective fields' (Schwartzman, 2010: 22). Thus, difficulty in learning does not reside only in disciplinary content - it cannot be separated from the learner, or the social context (Cousin, 2006).

Central to the TCF is the notion of liminality: coming to understand a threshold concept requires crossing a liminal space of uncertainty and incomplete understanding, making a recursive path from old to emergent understandings and views. This liminal phase may be emotionally charged, bringing uncertainty, anxiety, discomfort, and sometimes a sense of loss, as learners relinquish prior understandings (Cousin, 2006; Land, 2016; Meyer and Land, 2005; Schwartzman, 2010). Crossing conceptual thresholds is commonly associated with the acquisition or development of 'ways of thinking and practising' (WTP) in a discipline (Barradell and KennedyJones, 2013; McCune and Hounsell, 2005). Identity shifts ensue, because learning entails a process of 'becoming' (Barnett, 2009; Cousin, 2008) that changes how learners see themselves in relation to the disciplinary community - and perhaps also in relation to other communities to which they have belonged, or that they aspire to join (Davies and Mangan, 2007).

While students' responses to the challenges of liminality are central to their learning, the liminal traverse remains imperfectly understood. Representations of student experience are in relatively short supply within TCF scholarship (Schwartzman, 2010; Felten, 2016), and 'quite what supports or facilitates this [liminal] passage is not clear' (Rattray, 2016: 71). Emergent work has begun to consider the psychological and affective characteristics that influence how learners cope with the demands of the learning transition, but much of this is as yet exploratory or

\footnotetext{
${ }^{1}$ The term 'threshold concepts' has been used both to denote specific disciplinary ideas, and to refer to the analytic framework with its associated view of learning, body of scholarship and orientation in teaching (Schwartzman, 2010). We use 'TCF' for the latter.
} 
theoretical (Berg, et al., 2016; Rattray, 2016). A fuller understanding of the experiences and processes of disciplinary learning can reveal factors that may drive, hinder or help liminal crossings - and suggest pedagogic or curricular responses that might support the process.

We hope to contribute to this understanding, offering findings from a study that foregrounds students' perspectives, in a disciplinary and social context of intense learning challenges. Disciplinary difficulty is reflected in high failure and dropout rates, and concerns about the quality of learning and teaching in undergraduate economics, in South Africa and internationally (Colander and McGoldrick, 2009; Bokana and Tewari, 2014). The troublesome nature of economics has been linked to the abstractness of some of its fundamental concepts, the distinct way of thinking that defines the discipline, and the traditional ways in which it is taught. Our TCF-aligned programme in economics was thus fertile ground for in-depth exploration of disciplinary learning.

The next section describes the programme, and our use of Interactive Qualitative Analysis (IQA) (Northcutt and McCoy, 2004) to generate and analyse data. Thereafter, we present the students' conceptualisations of their learning. From these findings, we abstract a tentative model, from which we draw wider insights about the dynamics of disciplinary learning within a TCF orientation.

\section{Research methods: TC-oriented tutorials and IQA}

We explored students' learning in a tutorial programme that accompanied a standard, lectured module in Intermediate Microeconomics (Econ 202) at a South African university. Over the semester, a purposive sample of twenty volunteers (Creswell, 2013) from the mainstream class attended a ninety-minute tutorial each week. The small class size and additional time afforded by the programme allowed us to depart from traditional lectured delivery and use active, cooperative learning pedagogies, described below. The students wrote regular reflections on their learning over the course of the semester (Creswell, 2013), and participated in focus group sessions and individual interviews at its end (Northcutt and McCoy, 2004).

The tutorial tasks drew on teaching and learning activities from the Embedding Threshold Concepts (ETC) project ${ }^{2}$, mapped to relevant concepts from the mainstream syllabus. The microeconomic threshold concepts suggested by the ETC project coincided substantially with our sense (as teachers) of the topics students were most likely to experience as troublesome, transformative, and integrative. These included opportunity cost, economic modelling, marginality, and elasticity. The ETC teaching and learning activities are guided by a TC orientation (Davies and Mangan, 2006, 2007, 2008) that sets out to 'get students 'thinking like an economist' rather than simply being able to regurgitate concepts and models ... in an isolated fashion when given directed signals' (Davies and Mangan, 2006: 1). The exercises are intended to encourage active learning, using a variety of relatable, real-world topics that engage students' interest. Each exercise embeds thresholds concepts in a case or example that students are guided to analyse.

\footnotetext{
${ }^{2}$ This collaborative project hosted by Staffordshire University ran from 2004 to 2008 . Teaching materials are freely available from the project website: http://www.staffs.ac.uk/schools/business/iepr/etc/index.htm.
} 
Given the view of disciplinary threshold concepts as comprising a web that links theory and practice (Davies and Mangan, 2006), the exercises do not focus solely on one concept each, but aim instead to 'draw the students' attention to where these concepts are used as a way of developing their understanding of the conceptual framework within which economists operate', while also allowing them to 'revisit other previously introduced concepts within different applications and appreciate the patterns of thought within the discipline' (Davies and Mangan, 2006: 3).

Each tutorial in our programme was thus structured around an exercise focused on realworld or 'everyday' application of specific threshold concepts. Students worked on these activities in small-group discussion (four to six per group), which was followed in each session by class discussion, and oral or written reflection. In addition, participants wrote weekly reflections about their learning in economics. We expected this activity to have intrinsic value for the students, in that it could enhance their metalearning (Ward and Meyer, 2010).

In offering the tutorial programme, we were constrained by the mainstream course arrangements. Econ 202 is offered to several hundred students on two campuses, with common content and assessments, and we did not have leeway to depart from the pre-existing syllabus, or to redesign assessments to align with the pedagogical approach in the tutorials. This may have meant that the potential impact of the tutorial programme was not fully realised. Moreover, we did not attempt to evaluate or measure participants' learning through programme-specific assessment instruments, but instead relied on students' self-reported experiences to obtain a deeper, qualitative understanding of the course of their disciplinary learning.

IQA (Northcutt and McCoy, 2004) is a systematic, protocol-driven research procedure in which participants are entrusted with analysing and interpreting the data they generate, with the researcher playing a facilitative role. IQA aligns with social constructivist research, and its use here resonated strongly with the emphasis the TCF places on students' experiences, because participants were deeply involved in exploring their learning. Moreover, by creating a transparent audit trail of the steps required according to rigorous, replicable rules, IQA mitigates issues of researcher bias commonly associated with qualitative research, and enhances validity and reliability (Northcutt and McCoy, 2004).

IQA is initiated in a focus group. Through silent brainstorming, participants generate a multitude of individual responses to the phenomenon. In this case, a series of issue statements prompted the students to describe the process of learning, the products of learning, their feelings, and their sense of self in relation to learning, in the Economics 202 module and the tutorial group, over the semester. The brainstorming phase is followed by analysis and interpretation, as the group arranges the responses into thematic clusters ('affinities') and assigns each affinity a descriptive name. Checking and refining occur until the group reaches consensual understanding of the meaning of each affinity. Participants then identify relationships of influence among those affinities. The researcher is able to identify the key 'drivers' and 'outcomes' in the group's understanding of the phenomenon, and to capture these affinities and their interrelationships in a Systems Influence Diagram (SID). The SID is a visual representation of the 
group reality: learning as conceived by the participants. In the second phase of IQA, the affinities and their interrelationships are elaborated in semi-structured individual interviews, adding richness and depth to the representations emerging from the focus group process (Northcutt and McCoy, 2004).

The affinities provided the basis for coding the interview transcripts and the participants' reflective writing. From the data, we assembled quotes for each affinity - 'specific examples of discourse that illustrate or allude to an affinity' (Northcutt and McCoy, 2004: 315). These in turn we organised into common or recurring themes to identify interpretive 'elements' of each affinity, and to describe the relationships between affinities. These sets of quotes form the source material for representation of the findings in IQA: rich, grounded descriptions, rendered in participants' own words.

\section{Students' conceptualisations of disciplinary learning: Affinities and influences}

In the focus group, participants identified and named six affinities: Group Dynamics; the Learning Journey; Economic Thinking; Goals; Personal Outcomes; and Feelings. These were the components of meaning of their learning in the tutorial programme in economics. They also identified the directions of influence among these affinities. We begin this section by presenting the affinities, relying largely on excerpts from the composite quotes to capture the essence of each in the students' words. Thereafter, we consider the Systems Influence Diagram showing how these affinities relate to each other in a system of cause and effect (Northcutt and McCoy, 2004).

\section{Affinities: Elements of students' learning in economics}

Group Dynamics encompasses all the qualities and processes that defined students' interactions during the tutorial group sessions, and that they saw as impacting on their learning of economics:

I realised that I wasn't alone in 'the economics struggle'! I don't have to do it all on my own ... we can navigate around problems together till we find a solution. We all related in the TC tuts, and if I wasn't sure about something, I'd ask my colleagues - friends who are really intelligent people. By myself ... I can cram everything up, and just put it in my brain without understanding it. But then in the group I got understanding. Having people explaining different views, it comes together and forms an entire picture ... you're kind of building your own view. When we start to talk about things, that's when I comprehend and understand things - when you share, when you speak, you're learning. I discovered that some of the things I thought of were helpful, they were useful.... I learnt to trust my mind. That's how the group dynamics helped me the most - it was just being around the guys who already have it. It's just like home in the TC groups - I became more comfortable and more outspoken. Like having our own forum as economists in the making ... the people you can relate with, the people who can understand your language. 
The Learning Journey describes students' progression in learning economics and comprises two sub-affinities: (metacognitive) Learning about Learning and (conceptual) Stumbling Blocks and Successes encountered on the way to disciplinary understanding:

Putting all the information in my head in such a short space of time [in traditional lectures] ' a lot of it is just memorised stuff more than it's really knowledge. Learning economics in a deeper way [in the tutorials] helps me a lot in understanding. I need to know why the theory applies as it is. We were looking at different real-life situations and applying those concepts. I like that because it doesn't feel useless. I was lacking good learning styles and also encouragement, and these were caused by the poor school where I had some teachers that were not very good. When it came to the test I couldn't reflect or apply my knowledge on paper … [On feeling stuck on content]: I'd always think that ughhh, I must be stupid or something, I really don't understand what's going on. I'm kind of getting it now $\cdots$ it's still something that I need to work on, keep going over and over. [On finally understanding economic concepts or techniques]: So understanding that was a revelation. It broadened my understanding of the economic way of thinking. All those concepts or principles $\cdots$ were suddenly making sense.

Economic Thinking referred to the distinct disciplinary perspective students saw themselves developing:

It's when I try to relate the real situation that I have been in with what we have learnt - be able to apply the economic concepts in our daily lives. The way I'm thinking now is different from last year. You don't just see what everyone else is seeing, you see a bigger picture. I feel more confident knowing what's going on around me. The language [of economics] is actually different, for example opportunity cost and explicit cost $\cdots$ There are times when I even use economic terms $\cdots$ A long time ago it was just a course $\cdots$ [but now] it's becoming a part of me, and I'm starting to like it even more, because now I can see I can do it, and you know it's just in me now. 'Thinking like an economist' - I've become one of those people.

The Goals affinity - representing future plans or aspirations - showed the most variation in terms of meanings participants ascribed to it. Four students described Goals in narrow, performance-oriented terms:

My overall goal is just to pass ... just to get my degree ... passing economics, getting over it ... Most students think economics is ... just part of BCom requirements so they just want to get it over and done with. They don't see the value of doing economics. 
Others pointed to an intrinsic desire for understanding of economic phenomena:

I have developed an interest in economics, why people behave the way they do ... I want to deepen my understanding, to know more about it ... [because] it lives around us, we get to apply it in most of the situations that are happening.

Some students described Goals in terms of conscious, long-term intentions that informed their study choices and evolved as their plans solidified:

What you want to achieve, what you want to do, so it's basically about your own individual assessment of yourself. And where you're going in life, in your studies and everything else ... That's why I took economics. I wanted to do economics, that's true, but ... now it's fixed, I know that I really want to continue ...

Personal Outcomes embodied a range of benefits - academic, social and personal - that students ascribed to their learning on the tutorial programme:

I know what to do now next time, in terms of studying and the things that l've learnt. I developed in my academic world. I think that my mind is more open, not just in class, and not just in the module that I'm studying, but in all the other modules. I need to understand the concepts of things ... and not just be cramming things in my mind. You feel more confident ... in your work, more confident to share your ideas. I can talk about economics on any other courses with confidence. I've grown as a person. I got to discover myself. That's when I got to think like an economist, and I got to do things differently.

Notably, participants who had defined their Goals as simply to pass recounted a narrow range of Personal Outcomes (passing tests, making friends, or feeling compelled to study), while those who had emphasised a desire for understanding or longer term plans tended to elaborate on several benefits.

Feelings describes the spectrum of positive and negative emotions that arose from and affected students' learning.

Apprehending new content could bring fear and frustration, but also the joy of mastery:

During [lectures] ... I'll always feel like scared, ok now I'm not concentrating! That feeling of fear, ok I'm going to fail, I don't know what [the lecturer] is talking about ... I was stressed about actually getting things instead of just trying to understand, so I easily got stuck on some things, because l'd try to understand it and it doesn't go in ... You feel like giving up. Finally understanding something, that would make me feel 
like, ahh great, l'd feel more enthusiastic to get on to the next thing and to just go on. It felt great learning and attaining economic knowledge.

Disciplinary content itself could evoke uncomfortable emotions:

Thinking about what all my opportunity costs are made me sad, realising what was being given up. It is sad how one has to choose. I can't think like that, my feelings get in the way ... You can't walk around thinking 'I want to maximise my benefits, I don't care what happens to someone else!'

Feelings also arose from the anticipation and the results of assessment:

I wish I knew how to overcome my fear of economics assessments. Yoh, economics makes me very anxious. I think it's because I failed it a couple of times. [My test performance] ends up making me sad and angry at myself. ... When I saw that I had passed, I was really surprised (and VERY happy) ... that's when I knew I've got to keep going.

The learning programme itself elicited positive emotions and changed attitudes to economics:

Being part of the TC group made me feel kind of important; valuable. [I] felt good 'cause people would listen when I speak in the tut. I found the tuts to be fun and engaging ... I actually concentrated for the full two hours. I'm really enjoying the tutorials; I can't wait for the next class. I like [economics] more now since I know more or less when I can use it. I learned how to use it better, and as I use it, I love it more.

These six affinities, and their influences on each other, made up the participants' representations of their learning. IQA processes allow for the designation of 'driver' and 'outcome' affinities, and the specification of the key explanatory relationships among them, based on the frequency of participants' responses (Northcutt and McCoy, 2004). Following IQA protocol led us to construct the SID below, which captures how the group theorised the interrelationships among the affinities. 


\section{Explaining affinity interrelationships: Systems Influence Diagram}

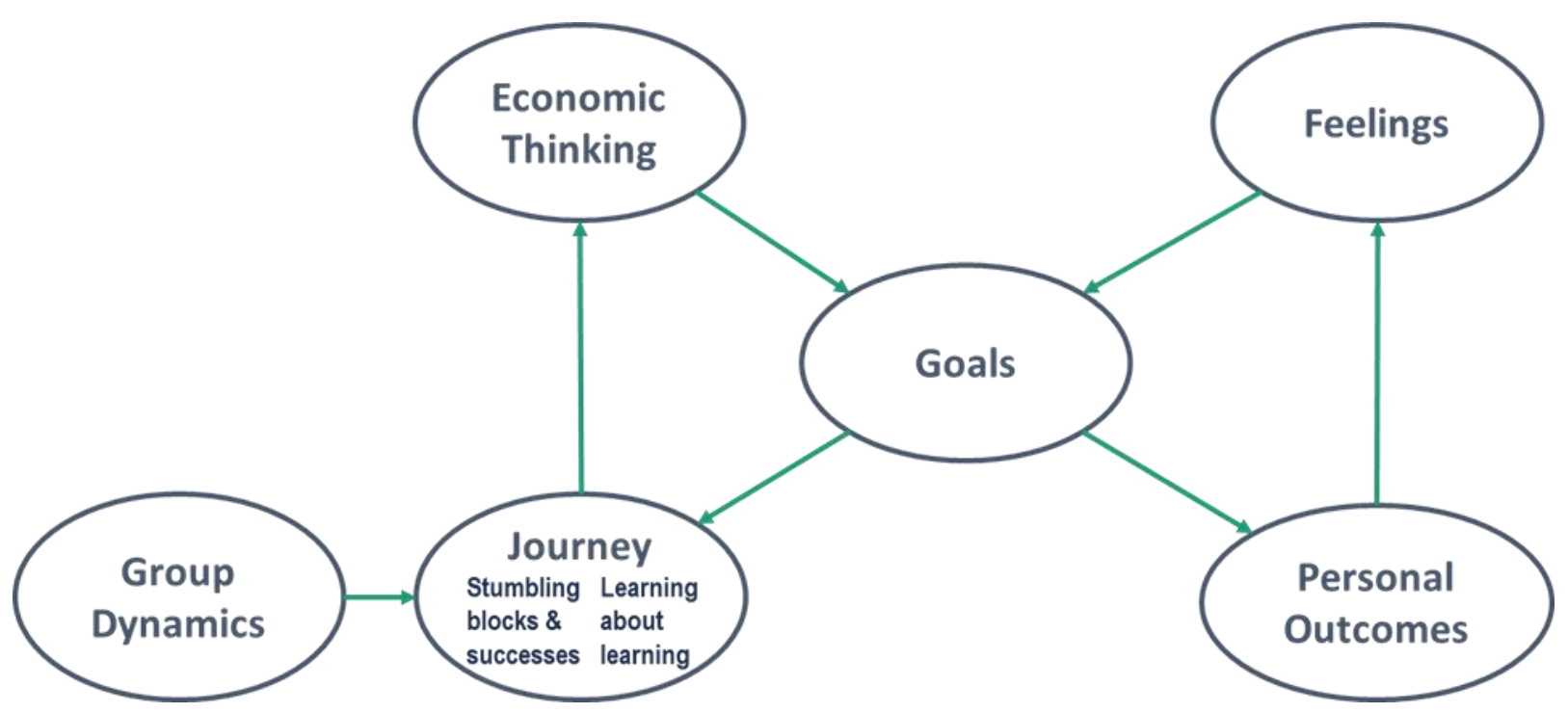

Figure 1: Systems Influence Diagram: Students'learning in the TC programme

The structure of the SID offers a way of understanding how the students viewed the dynamics of their learning. Each oval represents an affinity, and the arrows indicate directions of influence. Group Dynamics was the primary driver of the system, impacting on every other affinity. The Learning Journey and Economic Thinking were influential secondary drivers, while Goals, Personal Outcomes, and Feelings were outcomes in the overall system. Two interconnected sub-systems can be discerned: Journey - Economic Thinking - Goals, and Goals - Personal Outcomes - Feelings. We use this structure together with the affinity descriptions above to expand on students' theorising of these elements of learning and relate this understanding to extant literature.

Group Dynamics influenced the Learning Journey, and in turn the entire system, by enabling and supporting cognitive, metacognitive, and affective aspects of learning. Through processes of discussion and articulation within the group, students constructed understanding of economic concepts; they recognised this understanding based on 'knowing why' as being quite different to the memorisation they had tended to resort to in response to traditional lectured delivery. The driving role accorded to Group Dynamics signals the value of social interaction and discourse in the construction of disciplinary knowledge (Entwistle, 2009; Perkins, 2006), and the importance of 'reflective discourse' for transformative learning (Mezirow, 2000). The distinction students made between 'cramming' and understanding aligns with notions of deep and surface learning (Marton and Säljö, 1976); their emphasised intent - 'knowing why' - defines a deep approach (Entwistle, 2009).

Participants' experience of cooperative learning in the tutorials was accompanied by a sense of solidarity, empowerment, and capability, where before many had felt anxiety and selfdoubt. In the tutorial programme, the usual interconnected relations of power and pedagogy 
(Savin-Baden, 2006) were dismantled as responsibility for meaning-making was transferred to the group, directly encouraging students to see themselves as active agents in their learning (Barradell and Kennedy-Jones, 2013). The tutorial interactions afforded students positive experiences of factors that fed their perceptions of self-efficacy: personal accomplishments, vicarious learning experiences, verbal persuasions, and physiological and emotional states (Bandura, 1977). Participants valued thinking and learning as a collective - a counterpoint to the individualist traditions of 'Western' higher education that prevail in South African universities (Backhouse and Adam, 2013) - as competitiveness was replaced by solidarity and synergy which promoted their conceptual and metacognitive development. Moreover, the tutorials provided needed opportunities for social integration and growing friendship networks and offered 'refuge and prospect' to students (Land, 2016), serving as a risk-free space in which to rehearse economic WTP and find their disciplinary voice. Participants' descriptions of Group Dynamics were both wide-ranging and unanimously positive, suggesting that in the process of learning, peers and personal empowerment were as important as the pedagogy with which they were entwined.

New conceptions of knowledge and learning, and of themselves as capable learners, were important metacognitive shifts that made up Learning about Learning, one component of the overall Learning Journey affinity. The other was Stumbling Blocks and Successes - particular economic concepts and techniques that were (at least initially) sources of trouble. Disciplinary learning was not an automatic process, and a few participants noted that they still did not feel they had 'got it' by the end of the course, despite their positive views of the tutorial programme. Others felt that the disappointing results they obtained in module assessments belied the conceptual understanding they had reached. (This might suggest a misalignment between students' learning in the tutorials, and the mainstream assessment practices to which they were subjected, although we cannot substantiate this without having formally evaluated learning in the programme.)

Difficulty and 'stuckness' were commonplace, and their primary source seemed to be in the abstract nature of many economic concepts. The 'troublesome' (Perkins, 2006) aspects of some economic ideas, and students' descriptions of feeling stuck, of needing multiple 'takes' on a concept, and of the time required to reach understanding, suggest that these concepts were experienced as thresholds (Meyer and Land, 2005; Cousin, 2008). Seeing the use of economic concepts through relatable applications facilitated understanding. Students' sense of agency was enhanced as they felt they were gaining worthwhile, empowering knowledge which they experienced as personally relevant.

Comprehending particular concepts and techniques was often experienced as a breakthrough that enabled understanding of related ideas - akin to threshold crossing (Meyer and Land, 2006a). Cumulatively, these understandings constituted the development of Economic Thinking, which afforded students a changed perspective on real-world events. This economic gaze would be associated with new 'habits of mind' and 'points of view' (Schwartzman, 2010), or the internalising of disciplinary WTP (McCune and Hounsell, 2005). Economic Thinking also manifested in mastery of economic language, which became an expression as well as a means of 
learning (Meyer and Land, 2006a) and enabled students to feel they were full participants in the disciplinary community.

Goals, Personal Outcomes, and Feelings were the 'outcome' affinities. Students' Goals played a central role in their learning. Their words recall notions of 'performance' and 'mastery' (or 'learning') goal orientations from work on motivation and self-regulated learning, and support the view that mastery goals seem to foster deep learning approaches, while performance goal-orientation is linked to superficial learning strategies like memorisation (Pintrich, 2003; Zimmerman and Schunk, 2008).

Goals could guide learning behaviour and provide motivation to persist when disciplinary difficulty made demands on students' psychological capital (Rattray, 2016). Mastery goals are associated with deeper student engagement - greater cognitive investment in, active participation in, and emotional commitment to their learning. Variation in the depth of student engagement may be an important reason for variation in students' understanding of threshold concepts (Zepke, 2013). An important factor was the extent to which students felt that it was their choice to study economics, which in turn depended on their finding the disciplinary content relevant and meaningful. The conjunction of personal interest, autonomy, and self-determination here exemplifies intrinsically motivated learning (Pintrich, 2003).

Goals could thus shape both the course of the Learning Journey, and students' Personal Outcomes - the academic, social, and personal development benefits they ascribed to their learning in the programme, and which encompassed entwined processes of 'intellectual maturation' and 'disciplinary enculturation' (Cousin, 2008: 263). For some, learning precipitated shifts in their sense of themselves, tied to 'becoming' through coming to know in disciplinary ways (Barnett, 2009), and to their participation in the group, which had identity implications akin to a community of practice (Wenger, 1998).

Feelings - affective responses, both positive and negative - emanated from learning and engaging with content, from assessment, and from the learning environment. Participants voiced strong positive emotions associated with the peer group and learning approach, their awareness of disciplinary mastery, and their own personal growth. More difficult feelings arose from the liminal nature of conceptual learning (Cousin, 2006; Meyer and Land, 2006b), and from grappling with disciplinary content. Participants also described routine anxiety linked to self-doubt, the pressure to absorb rapidly delivered content, and the prospect of assessment, that might be rooted in personal and learning biographies (Crossman, 2007). To deal with these affective challenges, they had to tap their intrapersonal psychic resources (Rattray, 2016). Participation in the programme was helpful in that it built their self-belief and provided a sense of solidarity. The range of positive and negative feelings they experienced could lead students to revise or confirm their Goals, in turn influencing their learning choices and behaviour - their engagement in learning - for better or worse (Zepke, 2013).

The Learning Journey and Economic Thinking, together with the Goals affinity, form a positive feedback loop (a self-reinforcing sub-system) in the SID: participants' progression in learning engendered a shift to an economic way of thinking, which influenced their academic 
and career goals, which in turn 'fed back' to affect the course of learning. We termed this the 'Head' loop, because of its relatively cerebral nature, encompassing primarily conscious and deliberate aspects of learning.

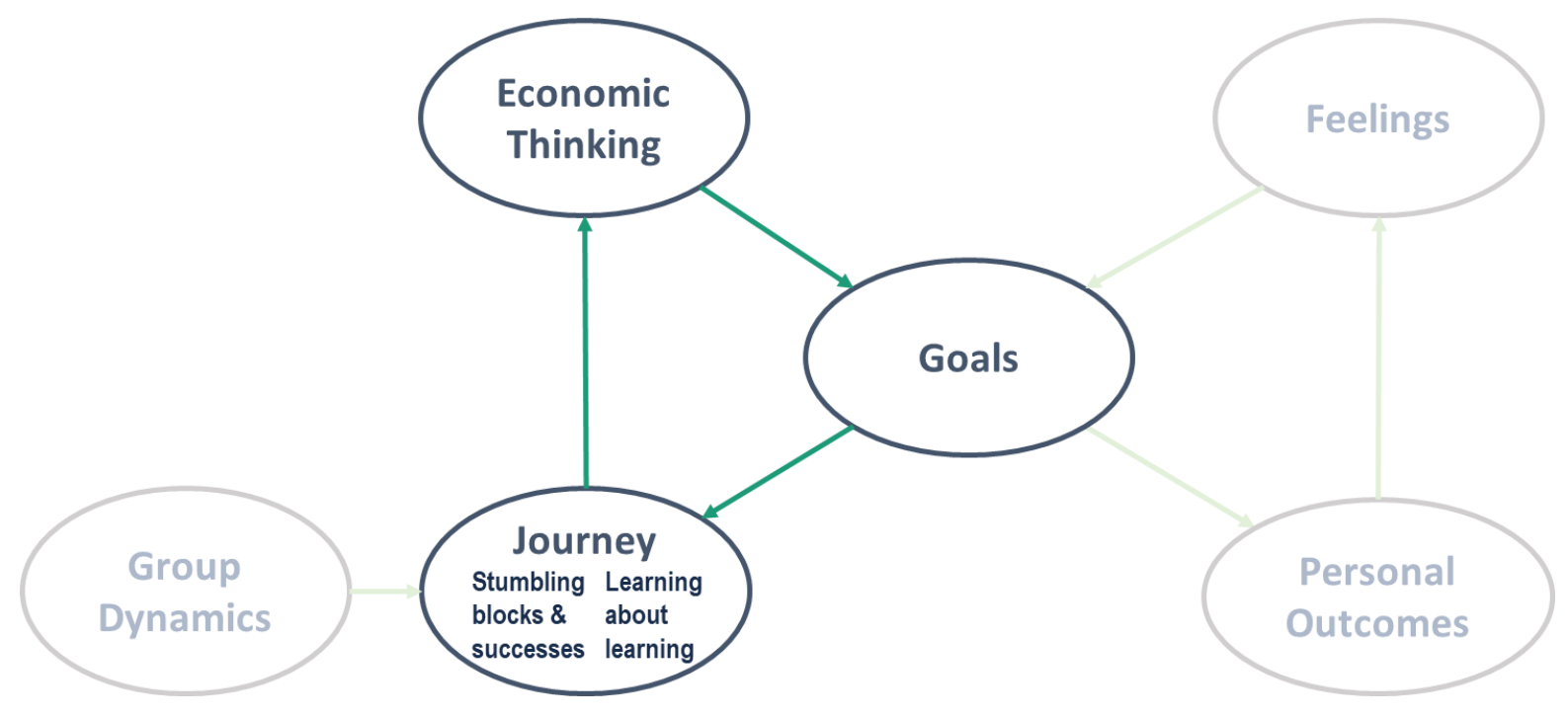

Figure 2: Systems Influence Diagram: The 'Head' loop

Goals, Personal Outcomes and Feelings were closely tied in a second potentially selfreinforcing sub-system embodying the affective, volitional, and identity-relevant aspects of individual learning. We called this the 'Heart' loop.

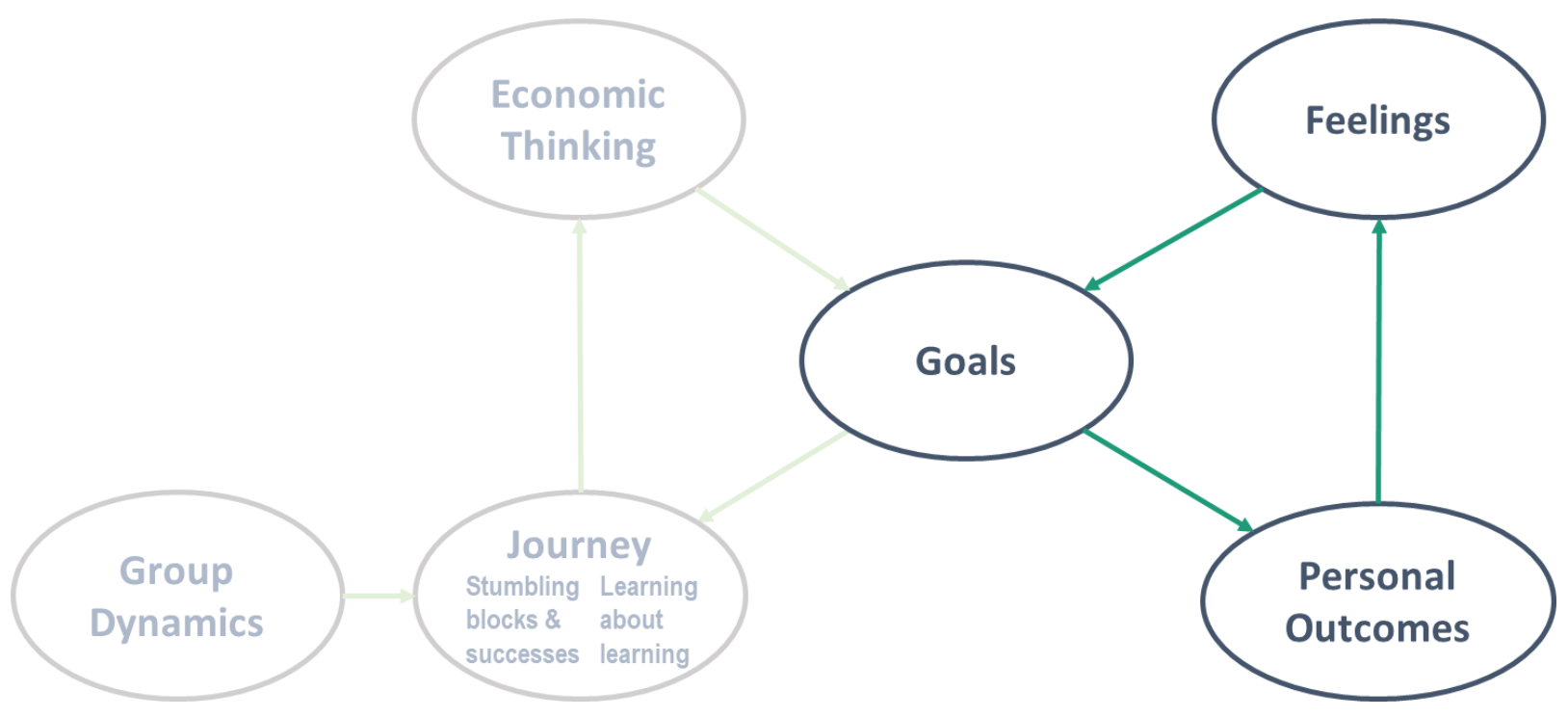

Figure 3: Systems Influence Diagram: The 'Heart' loop

Because Goals mediated and fed back the influence of emotional responses and personal growth into the more cognitive side of learning, students' conceptions of Goals can be seen as 
connecting the cognitive to the volitional and affective aspects of learning - the Head to the Heart loop. The circularity of the system and the interconnection of the two self-reinforcing loops mean that Goals, Personal Outcomes, and Feelings, although designated 'outcome' affinities, may also be strongly causal within the system of students' learning.

\section{Towards a model of disciplinary learning}

From these findings, we abstracted a view or model of students' learning in the programme, represented in the schematic below. We argue that this view may offer transferable insights and have explanatory and predictive potential for disciplinary learning in general.

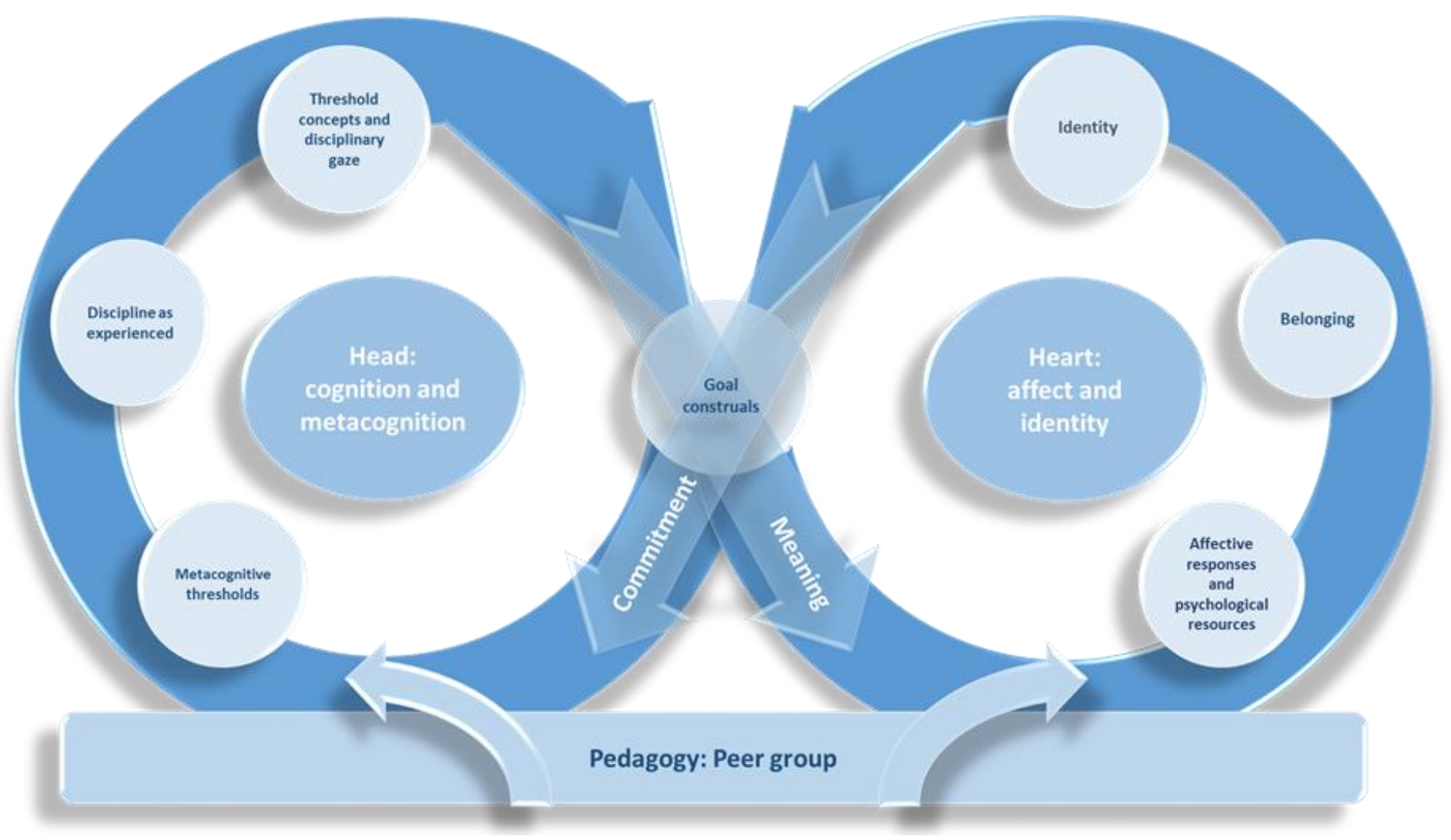

Figure 4: A model of disciplinary learning

Learning, in the diagram, comprises two loops: The Head and Heart aspects are equally important, connected, and - potentially - mutually reinforcing in a perpetual process of growth and transformation. The lemniscate (figure of eight) in the schematic evokes the continuous and non-linear path of transformative learning and recalls the structure of the SID. Each of the Head and Heart loops has interrelated components, or elements of learning and transformation, depicted in the seven discs. These elements are neither sequential nor discrete; they mutually affect each other, and their influences infuse into the overall flow. Each element may vary in 'value' according to individual or context; each may be experienced as positive or negative, 
conducive or not, complete or partial. Optimal learning will be favoured if all take on positive or conducive values; on the other hand, variation in each can, in interaction, give rise to a multiplicity of different individual experiences and consequences of learning. Together, these elements may be used to explain the 'happy path' of disciplinary learning (in the programme, and perhaps more broadly) and also to suggest possible reasons why, despite conducive pedagogies, some students may not realize deep and transformative learning.

The schematic shows learning as supported by the pedagogical approach - cooperative learning in the peer group - which positively influences both Head and Heart aspects in a multitude of ways. The constructs or elements of learning represented in the discs are briefly elaborated here.

Embarking on deep disciplinary learning requires that students cross metacognitive thresholds. Learning requires them to see knowledge not as a fixed body of disciplinary 'truth' to be absorbed and reproduced, but as being socially constructed. Accordingly, conceptions of learning shift from a focus on memorization, to a process of understanding based on 'knowing why', in which they are active and capable agents. In their transformative and enabling capacities, these changed views of knowledge, learning, and self as a capable learner may be characterized as metacognitive thresholds to further (disciplinary) learning, which must be crossed if students are not to remain stuck in superficial learning.

The discipline as experienced comprises students' encounters with the discipline through their studies, including in this case both mainstream lectures and the tutorial programme. The discipline as experienced is determined to a large extent by teachers' curricular and pedagogical choices.

Progress in disciplinary learning entails reaching understanding of particular concepts and techniques. This process may be characterized as crossing conceptual thresholds, because of the transformative, integrative and troublesome nature of reaching understanding. Cumulatively, these conceptual transformations give rise to a disciplinary gaze - a transformed way of viewing and interpreting real-world events. This is accompanied by increasing fluency in the language through which disciplinary understanding may be expressed. The shift in subjectivity resulting from this new perspective on reality can change learners' sense of self.

Students' goal construals in relation to learning exist at the intersection of cognitive, discipline-content elements and affective, identity-relevant aspects of learning, and play a central role in motivating and guiding their learning choices, behaviour and achievements. Goal construals include whether students have a performance or mastery goal-orientation, which influences whether they will tend to take a deep or surface approach to disciplinary learning. Goal construals also include the extent to which students have formed reflective, long-term goals based on a sense of autonomy and a perception that their learning in the discipline contributes to their plans and aspirations in some way. Goals are malleable and dynamic and may be influenced by the other elements of learning. Because goal construals are closely tied to identity and shaped by feelings, they connect the cognitive and largely conscious elements of the Head loop with the affective and personal Heart loop. 
A range of emotions arise from, and impact upon, the elements of learning; these make demands on learners' psychological resources. The interplay of affective responses and psychological resources constitutes an important element of learning. Affect may be evoked by any aspect of learning, including the pedagogical approach, disciplinary content, assessment practices, and other features of the learning environment; affective responses are widely variable, and may be strongly positive or negative. Effective learning requires that students modulate the negative and harness positive emotional responses, drawing on their internal psychological resources - the intrapersonal constructs that sustain commitment to learning goals and enable persistence in the face of difficulty. These might include fortitude, determination and resilience, self-belief, optimism and hope. Importantly, these resources are not fixed and may be supported and developed in the course of learning.

The element of belonging represents the extent to which the learning environment fosters a sense of safety, comfort and community that enables the expression of students' developing disciplinary understandings and emerging identities. A sense of belonging - within the peer group, the institution, or the discipline - supports affective, identity-related aspects of learning.

Students' identity or self-concept affects and is affected by the progress of their disciplinary learning. This sense of self includes appraisals, values, and aspirations originally formed by individual biography, which may evolve to include a stronger disciplinary identity in response to changing perspectives, personal growth and increased capacity for self-expression in academic and social domains. A sense of belonging may be instrumental in facilitating students' 'becoming' with regard to the discipline.

The overall working of the model centres on the connection of Head and Heart loops. Congruence between the discipline as experienced and students' self-concepts can foster mastery goals and identity-relevant, meaningful learning, leading to positive affective responses and affirmation of identity. This is portrayed by the 'Meaning' arrow linking the Head to the Heart loop. Affect in turn influences and is mediated by goals, as learners draw on their individual psychological resources to bring about a commitment to learning choices and behaviours, which in turn lead to positive impacts in cognitive and metacognitive learning domains. This effect is shown in the 'Commitment' arrow from the Heart to the Head loop. Conversely, if students' goals as informed by their self-construals are not served by the discipline as experienced, the Heart loop may not be activated, and learning may stall at a superficial level as students' affective and conative resources will not be sufficiently engaged to sustain them through the challenges of disciplinary learning. The importance of individual goal construals is evident, because commitment would be fostered by students' having reflective, learning-oriented, longer term conceptions of their goals, in terms of which their disciplinary learning may be perceived as relevant to their career plans, or simply to their sense of themselves in the world.

\section{Concluding thoughts}

To realize deep, transformative disciplinary learning, students have to engage both head and heart in the process. Because of the pivotal role of students' goal construals - which in turn 
depend on the alignment of the discipline as experienced with their sense of self - the work of discipline teachers may be seen to be elevated from (primarily) conveying discipline content, to illuminating its relevance and enhancing its meaning. We are called on not only to look critically at what we teach, and consider whether it is appropriately selected and structured to support conceptual threshold crossings, but also to create space and reason for students to reflect on this disciplinary learning, and on its relation to themselves. In order to do this, we need to pay attention to who our students are and what matters to them.

Prospective research might more closely examine the interconnection of learners' identity with the discipline as they experience it, and thereby seek to validate the model's elements particularly, the 'meaning' and 'commitment' vectors - in different social and disciplinary contexts.

If we can engage students with content that is personally relevant and meaningful, empower them through teaching approaches that allow them to see themselves as capable learners in the discipline, and offer supportive learning environments and relationships that can foster a sense of belonging, this may promote greater discipline-self congruence, enhanced learning and the emergence of an expanded, clearer sense of self, opening up our perspectives on what it means to learn, and to teach, in higher education.

\section{Acknowledgements}

This work is based on research supported in part by the National Research Foundation of South Africa (UNIQUE GRANT NO: 98274), and by a University of KwaZulu-Natal Competitive Teaching and Learning Research Grant.

\section{Author Biographies}

Jessica Schroenn Goebel has a PhD in Education from the University of KwaZulu-Natal, where she is a senior lecturer in the School of Accounting, Economics and Finance. Her current research interests centre on teaching, learning and curriculum in Economics higher education.

Suriamurthee Maistry leads "The South African Textbook Research Project", "The Higher Education Pedagogy Project", a series of case studies of curriculum and pedagogy in selected Economic and Business Sciences programmes and the "Decolonising Postgraduate Supervision" project which focuses on supervision practices in the context of decolonization debates.

\section{References}

Backhouse, J. \& Adam, F. 2013. The student experience in South Africa. In Kandiko, C. \& Weyers, M. (eds.) The Global Student Experience: An International and Comparative Analysis. Abingdon: Routledge, 228-246.

Bandura, A. 1977. Self-efficacy: Toward a unifying theory of behavioral change. Psychological Review, 84(2): 191-215. 
Barnett, R. 2009. Knowing and becoming in the higher education curriculum. Studies in Higher Education, 34(4): 429-440.

Barradell, S. \& Kennedy-Jones, M. 2013. Threshold concepts, student learning and curriculum: Making connections between theory and practice. Innovations in Education and Teaching International, 52(5): 536-545.

Berg, T., Erichsen, M. \& Hokstad, L. 2016. Stuck at the threshold: Which strategies do students choose when facing liminality within certain disciplines at a business school? In Land, R., Meyer, J. H. F. \& Flanagan, M. T. (eds.) Threshold Concepts in Practice. Rotterdam: Sense Publishers, 107-118.

Bokana, K. G. \& Tewari, D. D. 2014. Determinants of student success at a South African university: An econometric analysis. Anthropologist, 17(1): 259-277.

Colander, D. \& McGoldrick, K. (eds.) 2009. Educating Economists: The Teagle Discussion on ReEvaluating the Undergraduate Economics Major. Cheltenham: Edward Elgar.

Cousin, G. 2006. An introduction to threshold concepts. Planet, 17: 4-5.

Cousin, G. 2008. Threshold concepts: Old wine in new bottles or new forms of transactional curriculum enquiry? In Land, R., Meyer, J. H. F. \& Smith, J. (eds.) Threshold Concepts within the Disciplines. Rotterdam: Sense Publishers, 262-272.

Creswell, J. W. 2013. Qualitative Inquiry and Research Design: Choosing among Five Approaches (3rd ed.). Thousand Oaks, CA: Sage.

Cross, M. \& Carpentier, C. 2009. 'New students' in South African higher education: Institutional culture, student performance and the challenge of democratisation. Perspectives in Education, 27(1): 6-18.

Crossman, J. 2007. The role of relationships and emotions in student perceptions of learning and assessment. Higher Education Research \& Development, 26(3): 313-327.

Davies, P. \& Mangan, J. 2006. Embedding Threshold Concepts - a project of the Institute for Education Policy Research at Staffordshire University. Available at: http://www.staffs.ac.uk/schools/business/iepr/etc/index.htm (accessed 21 January 2017).

Davies, P. \& Mangan, J. 2007. Threshold concepts and the integration of understanding in economics. Studies in Higher Education, 32(6): 711-726.

Davies, P. \& Mangan, J. 2008. Embedding threshold concepts: From theory to pedagogical principles to learning activities. In Land, R., Meyer, J. H. F. \& Smith, J. (eds.) Threshold Concepts within the Disciplines. Rotterdam: Sense Publishers, 37-50.

Entwistle, N. J. 2009. Teaching for Understanding at University: Deep Approaches and Distinctive Ways of Thinking. Basingstoke: Palgrave Macmillan.

Felten, P. 2016. On the threshold with students. In Land, R., Meyer, J. H. F. \& Flanagan, M. T. (eds.) Threshold Concepts in Practice. Rotterdam: Sense Publishers, 3-10.

Land, R. 2016. Toil and trouble: Threshold concepts as a pedagogy of uncertainty. In Land, R., Meyer, J. H. F. \& Flanagan, M. T. (eds.) Threshold Concepts in Practice. Rotterdam: Sense Publishers, 11-24. 
Marton, F. \& Säljö, R. 1976. On qualitative differences in learning: Outcome and process. British Journal of Educational Psychology, 46(1): 4-11.

McCune, V. \& Hounsell, D. 2005. The development of students' ways of thinking and practising in three final-year biology courses. Higher Education, 49(3): 255-289.

Meyer, J. H. F. \& Land, R. 2005. Threshold concepts and troublesome knowledge (2): Epistemological considerations and a conceptual framework for teaching and learning. Higher Education, 49(3): 373-388.

Meyer, J. H. \& Land, R. 2006a. Threshold concepts and troublesome knowledge: An introduction. In Meyer, J. H. F., \& Land, R. (eds.) 2006. Overcoming Barriers to Student Understanding: Threshold Concepts and Troublesome Knowledge. Abingdon: Routledge.

Meyer, J. H. \& Land, R. 2006b. Threshold concepts and troublesome knowledge: Issues of liminality. In Meyer, J. H. F., \& Land, R. (eds.) 2006. Overcoming Barriers to Student Understanding: Threshold Concepts and Troublesome Knowledge. Abingdon: Routledge.

Mezirow, J. 2000. Learning as Transformation: Critical Perspectives on a Theory in Progress. San Francisco: Jossey-Bass Publishers.

Northcutt, N. \& McCoy, D. 2004. Interactive Qualitative Analysis: A Systems Method for Qualitative Research. London: Sage.

Perkins, D. 2006. Constructivism and troublesome knowledge. In Meyer, J. H. F. \& Land, R. (eds.) Overcoming Barriers to Student Understanding: Threshold Concepts and Troublesome Knowledge. Abingdon: Routledge, 33-47.

Pintrich, P. R. 2003. A motivational science perspective on the role of student motivation in learning and teaching contexts. Journal of Educational Psychology, 95(4): 667-686.

Rattray, J. 2016. Affective dimensions of liminality. In Land, R., Meyer, J. H. F. \& Flanagan, M. T. (eds.) Threshold Concepts in Practice. Rotterdam: Sense Publishers, 67-76.

Savin-Baden, M. 2006. Disjunction as a form of troublesome knowledge in problem-based learning. In Meyer, J. H. F. \& Land, R. (eds.) Overcoming Barriers to Student Understanding: Threshold Concepts and Troublesome Knowledge. Abingdon: Routledge, 160-172.

Schwartzman, L. 2010. Transcending disciplinary boundaries: A proposed theoretical foundation for threshold concepts. In Meyer, J. H. F., Land, R. \& Baillie, C. (eds.) Threshold Concepts and Transformational Learning. Rotterdam: Sense Publishers, 21-44.

Ward, S. C. \& Meyer, J. H. F. 2010. Metalearning capacity and threshold concept engagement. Innovations in Education \& Teaching International, 47(4): 369-378.

Wenger, E. 1998. Communities of Practice: Learning, Meaning, and Identity. New York: Cambridge University Press.

Zepke, N. 2013. Threshold concepts and student engagement: Revisiting pedagogical content knowledge. Active Learning in Higher Education, 14(2): 97-107.

Zimmerman, B. J. \& Schunk, D. H. 2008. Motivation: An essential dimension of self-regulated learning. In Schunk, D. H. \& Zimmerman, B. J. (eds.) Motivation and Self-Regulated Learning: Theory, Research and Applications. New York: Routledge, 1-30. 